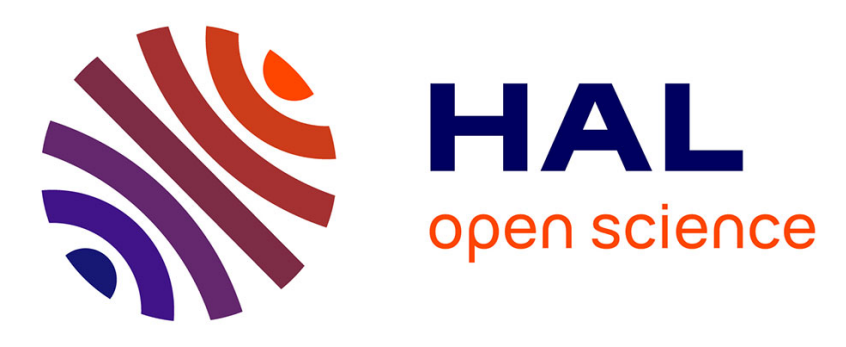

\title{
Bringing Advanced Analytics to Manufacturing: A Systematic Mapping
}

Hergen Wolf, Rafael Lorenz, Mathias Kraus, Stefan Feuerriegel, Torbjørn H. Netland

\section{- To cite this version:}

Hergen Wolf, Rafael Lorenz, Mathias Kraus, Stefan Feuerriegel, Torbjørn H. Netland. Bringing Advanced Analytics to Manufacturing: A Systematic Mapping. IFIP International Conference on Advances in Production Management Systems (APMS), Sep 2019, Austin, TX, United States. pp.333340, 10.1007/978-3-030-30000-5_42 . hal-02419212

\section{HAL Id: hal-02419212 \\ https://hal.inria.fr/hal-02419212}

Submitted on 19 Dec 2019

HAL is a multi-disciplinary open access archive for the deposit and dissemination of scientific research documents, whether they are published or not. The documents may come from teaching and research institutions in France or abroad, or from public or private research centers.
L'archive ouverte pluridisciplinaire HAL, est destinée au dépôt et à la diffusion de documents scientifiques de niveau recherche, publiés ou non, émanant des établissements d'enseignement et de recherche français ou étrangers, des laboratoires publics ou privés.

\section{(c)(1)}

Distributed under a Creative Commons Attribution| 4.0 International License 


\title{
Bringing Advanced Analytics to Manufacturing: A Systematic Mapping
}

\author{
Hergen Wolf ${ }^{1,2(凶)[0000-0003-3134-1900]}$, Rafael Lorenz ${ }^{1[0000-0001-7473-3328]}$, \\ Mathias Kraus ${ }^{1[0000-0002-2021-2743]}$, Stefan Feuerriegel ${ }^{10000-0001-7856-8729]}$, \\ and Torbjørn H. Netland ${ }^{1[0000-0001-7382-1051]}$ \\ 1 ETH Zurich, Weinbergstr. 56/58, 8092 Zurich, Switzerland \\ hewolf@student . ethz.ch \\ 2 TU Dresden, Helmholtzstr. 10, 01069 Dresden, Germany
}

\begin{abstract}
Advanced analytics has the potential to redefine manufacturing. However, practical implementation is in its infancy. One reason is a lack of management tools that enable decision-makers to choose suitable techniques from advanced analytics for domain-specific problems in manufacturing. This paper uses a systematic mapping review in order to identify seven application areas to which analytics can add substantial value. Each area is then matched with suitable techniques from the field of advanced analytics. The resulting systematic map provides a novel management tool for the purpose of identifying promising analytics projects in manufacturing and thus facilitates decision-making.
\end{abstract}

Keywords: Smart Manufacturing - AI Applications · Advanced Analytics · Systematic Mapping Review

\section{Introduction}

Advanced analytics offers new ways to improve and innovate manufacturing processes [5]10. Steady progress in terms of computing power and storage capacity, as well as the rapid development of advanced algorithms, has equipped companies with unprecedented possibilities to generate knowledge and business value from large datasets 1324 . In this way, analytics changes the basis of competition [10].

In order to thrive in today's competitive market environment, manufacturers can use advanced analytics to streamline complex operations while improving quality and reducing costs 22 25]. The manufacturing sector can benefit greatly from the use of advanced analytics, since data is abundantly available [16, providing a still largely untapped potential for process improvement and innovation. Manufacturing strategies, such as Industry 4.0 in Germany, Industrial Internet in the United States, and the Made in China 2025 initiative, recognize the strategic importance of utilizing data in order to enhance manufacturing competitiveness 21/22. However, manufacturers are not exploiting the full potential of data and analytics. Recently, McKinsey speculated that less than $30 \%$ of the potential has been captured so far [10]. 
A main barrier that prevents manufacturers from harnessing the full potential of analytics is a lack of management tools that enable decision-makers to choose suitable techniques from advanced analytics for domain-specific problems in manufacturing. While research has brought forward various techniques capable of solving complex problems in manufacturing, little has been done to equip practitioners and decision-makers with the necessary management tools to implement these techniques on an operational level 723 25].

This paper uses a systematic mapping review in order to identify seven application areas to which analytics can add substantial value. Each area is then matched with suitable techniques from the field of advanced analytics. The resulting systematic map provides a novel management tool for the purpose of identifying promising analytics projects in manufacturing and thus facilitates decision-making. To the best of our knowledge, such a management tool, one that matches application areas in manufacturing with analytics, does not yet exist.

\section{Background}

Several authors have attempted to define the vague term "analytics" and yet there is no universally accepted definition. In this paper, we adopt the definition put forward by Davenport et al. 6. p. 7], characterizing analytics as "the extensive use of data, statistical and quantitative analysis, explanatory and predictive models, and fact-based management to drive decisions and actions." With the term "advanced analytics", we subsume methods originating from statistical learning, e.g., data mining techniques, as well as methods stemming from artificial intelligence research, in particular machine learning algorithms.

Previous work in the field of analytics applications for manufacturing has predominantly been limited to systematic literature reviews $3[4|9| 12[18] 19]$. The available systematic literature reviews generally neglect to consistently systematize and link application areas with suitable analytics techniques in a structured and visually appealing way. A notable exception is Köksal et al. 12. However, a drawback is the limited focus on quality improvement tasks, rather than considering additional important application areas such as production planning, product inspection, or machinery maintenance.

Flath and Stein 8 , have developed an adapted data mining process model for manufacturing prediction tasks, proposing guidelines for modelling, feature engineering, and interpretation. However, similar to already existing generic process models, such as the cross-industry standard process for data mining (CRISPDM), their work does not provide decision support for the selection of suitable analytics techniques.

Villanueva Zacarias et al. 23] propose a framework that automatically recommends suitable analytics techniques with respect to a domain-specific problem at hand. Similarly, Lechevalier et al. [14] present a framework for the semiautomatic generation of analytical models in manufacturing and a proof-ofconcept prototype that allows practitioners to generate artificial neural networks 
for prediction tasks through a user interface. Both frameworks represent promising approaches tackling the problem of automated analytics technique configuration in the manufacturing domain. However, these concepts do not pursue the goal of identifying promising combinations of analytics and application areas in the first place. Therefore, both approaches are unsuitable for decision-making at the managerial level.

Table 1 stresses the research gap by reporting on related key literature. We explicitly searched for articles focusing on the fusion of both manufacturing application areas and analytics techniques. Evidently, existing solutions are either unsatisfactory or inadequate to facilitate the selection of suitable techniques from analytics for domain-specific problems in manufacturing. Although scholars have addressed the lack of decision support [7/25], no research has yet been devoted to comprehensively combining analytics with application areas in manufacturing.

Table 1. Selected key literature on analytics applications for manufacturing. Full circle indicates compliance with the respective criterion.

\begin{tabular}{|c|c|c|c|c|}
\hline 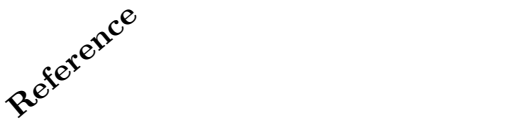 & $0^{x+e^{u^{x}}}$ & $59^{\circ}$ & $p^{v^{4}}$ & $x^{x^{c^{5}}}$ \\
\hline Pham and Afify (2005) [18 & Literature review & (1) & (1) & 0 \\
\hline Harding et al. (2006) [9] & Literature review & ○ & 0 & $\bigcirc$ \\
\hline Choudhary et al. (2009) 4 & Literature review & 0 & (1) & 0 \\
\hline Köksal et al. (2011) 12 & Literature review & 0 & (1) & ( \\
\hline Cheng et al. (2018) 3 & Literature review & (1) & (1) & $\bigcirc$ \\
\hline Sharp et al. (2018) 19] & Literature review & 0 & D & 0 \\
\hline Flath and Stein (2018) 8 & Process model & 0 & (1) & $\bigcirc$ \\
\hline Villanueva Zacarias et al. (2018) 23 & Framework & 0 & 0 & 0 \\
\hline Lechevalier et al. (2018) 14 & Framework & $\bigcirc$ & $\bigcirc$ & $\bullet$ \\
\hline This paper & Systematic map & 0 & 0 & 0 \\
\hline
\end{tabular}

\section{Methodology}

We used a systematic mapping review, following the guidelines of Petersen et al. [17, in order to design a management tool that facilitates analytics selection in manufacturing. The goal of a systematic mapping review is to build a twodimensional classification scheme, a map, to visually structure a research area. The analysis of results focuses on frequencies of publications for categories within the scheme, thereby creating a map which can easily help transfer knowledge to practitioners [17.

We chose Scopus to search for relevant literature, since it covers a broad, interdisciplinary field of research. The search was limited to journal articles written in English and published from 2008 until the end of 2018. This time frame 
of 11 years was regarded as sufficiently exhaustive, since research on analytics applications for manufacturing has only recently been addressed with growing interest [1921 25]. Furthermore, discrete-part and assembly manufacturing that are classified into division 26-30 by the International Standard Industrial Classification (ISIC) were designated as the target domains of this work. Manufacturing companies operating in these high-tech sectors (e.g., automotive, aerospace, machinery, and electronics) are profoundly affected by digital transformation processes [15] and are, therefore, ideally suited to the adoption of analytics. However, some of the mentioned application areas also exist in continuous manufacturing processes, such as oil refining and chemicals.

Our literature search was split into two parts in order to obtain relevant research articles. The first search 1 identified seven major application areas in manufacturing to which analytics can add substantial value, namely demand forecasting, job scheduling, product inspection, process diagnostics and prediction, machine parameter optimization, diagnostic maintenance, and predictive maintenance. The second search queried each identified application area independently using appropriate keywords ${ }^{2}$ From the entire corpus of 1,853 articles, 81 articles that reported a successful application of at least one machine learning method were considered in order to build the final systematic map. These 81 articles were selected according to their average number of citations per year in order to include widely appreciated research articles. A stop criterion limited the number of articles per application area to 15 (or fewer if articles were cited less than three times on average per year). The reading and selection process was solely conducted by the lead author of this paper.

We only considered analytics techniques applied for the final regression, classification, or optimization task, in order to facilitate an easy interpretation of the systematic map. This is a reasonable approach, since the way data is preprocessed primarily depends on the final technique applied [1. We agree with 25] that a promising approach to select a suitable machine learning algorithm is to look for problems of similar nature. Therefore, we are convinced that the frequency of published articles can be used as a valid proxy for the purpose of identifying suitable machine learning techniques for a specific application area.

\section{Results}

In the following, the main results of our research are presented. First, the identified application areas to which analytics can add substantial value are described

\footnotetext{
${ }^{1}$ TITLE(manufacturing OR ' 'smart production"') AND TITLE(data OR ai OR analytics OR learning OR artificial) AND TITLE-ABS-KEY(application).

${ }^{2}$ For instance, articles regarding machine parameter optimization were queried with: TITLE-ABS-KEY ("data mining') OR analytics OR learning OR "'artificial 
and pooled into three main groups, namely plan, make, and maintain. Afterwards, the map resulting from the systematic mapping review is presented.

\subsection{Application Areas of Analytics in Manufacturing}

Plan Demand forecasting and job scheduling are elements of the production planning processes of a manufacturing facility. Demand forecasting mostly uses historical time-series to predict future demand. Especially in large supply chains, demand forecasting can lead to a mitigated bullwhip effect [2]. Job scheduling applies optimization techniques in order to derive the actual production plan while making a trade-off between the impact of early or late completion of a task.

Make Product inspection, process diagnostics and prediction, and machine parameter optimization aim at optimizing manufacturing processes with regard to quality, time, and costs. Product inspection can use image data in order to analyze product states, for instance the surface quality of steel, and classifies items into scrap or good parts. Process diagnostics and prediction are two major quality improvement and control activities. Whereas process diagnostics primarily determines variables that significantly affect quality, process prediction models the relationships between input variables and output quality characteristics. Furthermore, process prediction is usually a preliminary step undertaken in order to optimize manufacturing machinery input parameters. Thus, it is closely linked to machine parameter optimization, which yields optimal machinery parameters with respect to a target quality measure, such as surface roughness, for instance. Adjusting technological processes in relation to these parameters can result in improved productivity and product quality, as well as reduced costs 21.

Maintain Diagnostic and predictive maintenance are two application areas that strongly build on each other [20], aiming to reduce downtime of manufacturing machinery and tool equipment. A new maintenance paradigm, condition-based maintenance, has gained considerable attention in recent years [19. Conditionbased maintenance utilizes online condition variables to detect, identify, and forecast potentially detrimental fault conditions. Current condition-based plans, designated as diagnostic maintenance, assess the current state of the system in real-time and perform maintenance when a triggering event occurs, such as the growth of a fault frequency beyond a particular threshold. However, a major drawback of diagnostic maintenance is that it cannot anticipate a breakdown well ahead of time. To overcome this, predictive maintenance looks at the current and past states of the system, as well as its expected future operational load, to predict how much remaining useful life a system has [19]. This temporal information advantage helps maintenance engineers to proactively order important spare parts that might not be immediately available. 


\subsection{Systematic Map}

The resulting systematic map is shown in Fig. 1 The vertical axis presents all seven application areas, while the horizontal axis reports on techniques from advanced analytics that are classified in a two-level taxonomy.

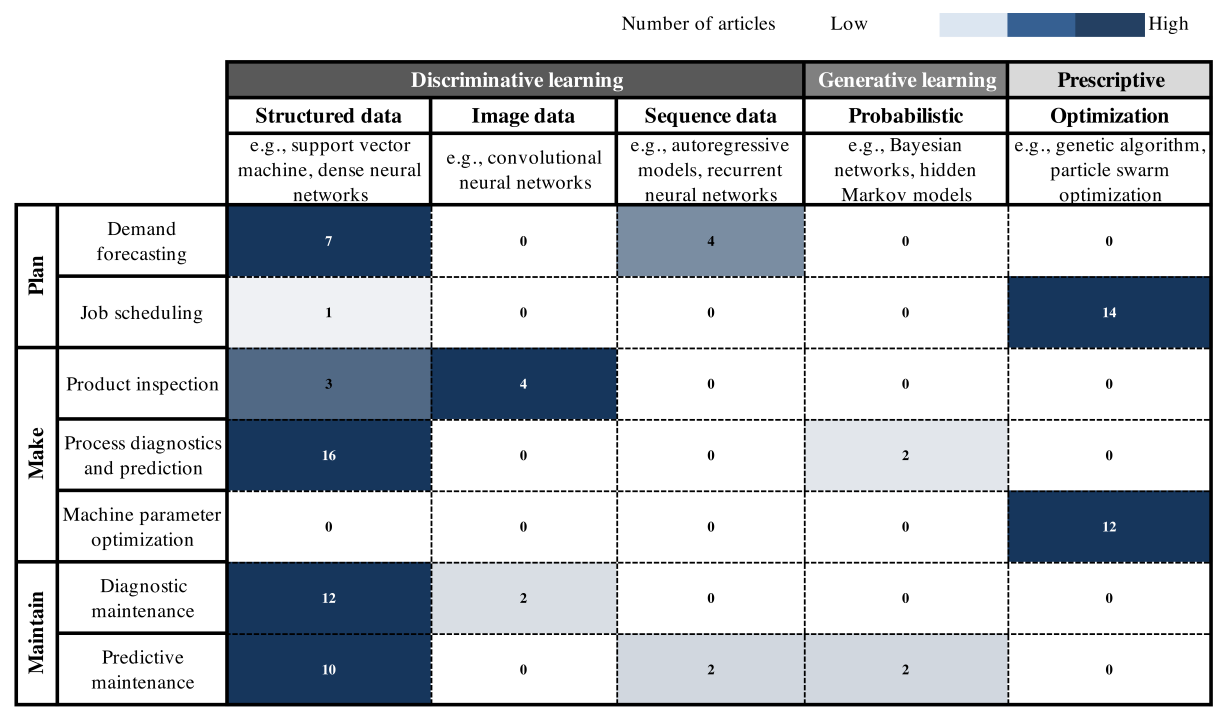

Fig. 1. Systematic mapping of techniques from advanced analytics (horizontal axis) to seven application areas in manufacturing (vertical axis). Color intensities represent the relative frequency of proposed analytics techniques with respect to an application area. The sum of the matrix is greater than 81 (number of reviewed articles) because some articles compared multiple analytics techniques.

Since most analytics techniques applied in manufacturing are of a supervised nature [25], we chose to differentiates between discriminative learning, generative learning, and prescriptive techniques on a first level [111]. On the second level, discriminative learning techniques are further subdivided into structured, image, and sequence data-based models to allow for a more granular interpretation of the map. Examples of the most commonly encountered techniques are given below. For each application area, color intensities represent the relative frequency of proposed analytics techniques.

Empirical evidence from 81 reviewed journal articles shows that optimization techniques have thus far been applied in the areas of job scheduling and machine parameter optimization. Discriminative analytics techniques based on image data, e.g., convolutional neural networks, have become the primary tool for automated product inspection. Discriminative analytics techniques that rely on structured data are mainly used for demand forecasting, quality diagnostics and prediction, as well as diagnostic and predictive maintenance. 


\section{Conclusion}

Advanced analytics is expected to have a significant impact on manufacturing. However, practical implementation is still in its early stages. One reason is that decision-makers have lacked management tools to choose suitable techniques from advanced analytics for domain-specific problems in manufacturing.

This paper applied a systematic mapping review to identify seven application areas to which analytics can add substantial value. Each area was then matched with suitable techniques from the field of advanced analytics. The resulting systematic map provides a novel management tool to identify promising analytics projects in manufacturing and thus facilitates decision-making.

Furthermore, the presented systematic map organizes interdisciplinary knowledge in a structured manner to serve as a means for common understanding in analytics projects. This is particularly helpful in order to bridge the gap between domain-specific manufacturing contexts and general-purpose analytics practices. In this way, collaboration between different stakeholders, e.g., domain experts and data analysts, can become a less complex and time-consuming task.

\section{References}

1. Bishop, C.M.: Pattern recognition and machine learning. Springer, New York, USA (2006)

2. Carbonneau, R., Laframboise, K., Vahidov, R.: Application of machine learning techniques for supply chain demand forecasting. European Journal of Operational Research 184(3), 1140-1154 (2008). https://doi.org/10.1016/j.ejor.2006.12.004

3. Cheng, Y., Chen, K., Sun, H., Zhang, Y., Tao, F.: Data and knowledge mining with big data towards smart production. Journal of Industrial Information Integration 9, 1-13 (2018). https://doi.org/10.1016/j.jii.2017.08.001

4. Choudhary, A.K., Harding, J.A., Tiwari, M.K.: Data mining in manufacturing: a review based on the kind of knowledge. Journal of Intelligent Manufacturing 20(5), 501-521 (2009). https://doi.org/10.1007/s10845-008-0145-x

5. Chui, M., Manyika, J., Miremadi, M., Henke, N., Chung, R., Nel, P., Malhotra, S.: Notes from the AI frontier: Insights from hundreds of use cases. McKinsey Global Institute (2018)

6. Davenport, T.H., Harris, J.G.: Competing on analytics: The new science of winning. Harvard Business School Press, Boston, USA (2007)

7. Dreyfus, P.A., Kyritsis, D.: A framework based on predictive maintenance, zerodefect manufacturing and scheduling under uncertainty tools, to optimize production capacities of high-end quality products. In: Advances in Production Management Systems. Smart Manufacturing for Industry 4.0, IFIP Advances in Information and Communication Technology, vol. 536, pp. 296-303. Springer International Publishing, Cham, Switzerland (2018). https://doi.org/10.1007/978-3-319-997070_37

8. Flath, C.M., Stein, N.: Towards a data science toolbox for industrial analytics applications. Computers in Industry 94, 16-25 (2018). https://doi.org/10.1016/j.compind.2017.09.003 
9. Harding, J.A., Shahbaz, M., Srinivas, Kusiak, A.: Data mining in manufacturing: A review. Journal of Manufacturing Science and Engineering 128(4) (2006). https://doi.org/10.1115/1.2194554

10. Henke, N., Bughin, J., Chui, M., Manyika, J., Saleh, T., Wiseman, B., Sethupathy, G.: The age of analytics: Competing in a data-driven world. McKinsey Global Institute (2016)

11. Jebara, T.: Machine Learning. Springer, Boston (2004). https://doi.org/10.1007/978-1-4419-9011-2

12. Köksal, G., Batmaz, İ., Testik, M.C.: A review of data mining applications for quality improvement in manufacturing industry. Expert Systems with Applications 38(10), 13448-13467 (2011). https://doi.org/10.1016/j.eswa.2011.04.063

13. Kraus, M., Feuerriegel, S., Oztekin, A.: Deep learning in business analytics and operations research: Models, applications and managerial implications, https:// arxiv.org/pdf/1806.10897.pdf

14. Lechevalier, D., Narayanan, A., Rachuri, S., Foufou, S.: A methodology for the semi-automatic generation of analytical models in manufacturing. Computers in Industry 95, 54-67 (2018). https://doi.org/10.1016/j.compind.2017.12.005

15. Leurent, H., de Boer, E.: The next economic growth engine: Scaling fourth industrial revolution technologies in production. World Economic Forum (2018)

16. Manyika, J., Chui, M., Brown, B., Bughin, J., Dobbs, R., Roxburgh, C., Byers, A.H.: Big data: The next frontier for innovation, competition, and productivity. McKinsey Global Institute (2011)

17. Petersen, K., Feldt, R., Mujtaba, S., Mattsson, M.: Systematic mapping studies in software engineering. 12th International Conference on Evaluation and Assessment in Software Engineering 8, 68-77 (2008)

18. Pham, D.T., Afify, A.A.: Machine-learning techniques and their applications in manufacturing. Proceedings of the Institution of Mechanical Engineers, Part B: Journal of Engineering Manufacture 219(5), 395-412 (2005). https://doi.org/10.1243/095440505X32274

19. Sharp, M., Ak, R., Hedberg, T.: A survey of the advancing use and development of machine learning in smart manufacturing. Journal of Manufacturing Systems 48, 170-179 (2018). https://doi.org/10.1016/j.jmsy.2018.02.004

20. Sikorska, J.Z., Hodkiewicz, M., Ma, L.: Prognostic modelling options for remaining useful life estimation by industry. Mechanical Systems and Signal Processing 25(5), 1803-1836 (2011). https://doi.org/10.1016/j.ymssp.2010.11.018

21. Tao, F., Qi, Q., Liu, A., Kusiak, A.: Data-driven smart manufacturing. Journal of Manufacturing Systems 48, 157-169 (2018). https://doi.org/10.1016/j.jmsy.2018.01.006

22. Thoben, K.D., Wiesner, S., Wuest, T.: "Industrie 4.0" and smart manufacturing: A review of research issues and application examples. International Journal of Automation Technology 11(1), 4-16 (2017).https://doi.org/10.20965/ijat.2017.p0004

23. Villanueva Zacarias, A.G., Reimann, P., Mitschang, B.: A framework to guide the selection and configuration of machine-learning-based data analytics solutions in manufacturing. Procedia CIRP 72, 153-158 (2018). https://doi.org/10.1016/j.procir.2018.03.215

24. Wang, J., Ma, Y., Zhang, L., Gao, R.X., Wu, D.: Deep learning for smart manufacturing: Methods and applications. Journal of Manufacturing Systems 48, 144-156 (2018). https://doi.org/10.1016/j.jmsy.2018.01.003

25. Wuest, T., Weimer, D., Irgens, C., Thoben, K.D.: Machine learning in manufacturing: Advantages, challenges, and applications. Production \& Manufacturing Research 4(1), 23-45 (2016). https://doi.org/10.1080/21693277.2016.1192517 